\title{
Application of Alkaline Pulping to Pruned Branches of Citrus limon from Sudan
}

\author{
Tarig KHIDER ${ }^{1, *}$, Safaa OMER ${ }^{2}$, Osman ELZAKI ${ }^{3}$, \\ Salaheldin MOHIELDIN ${ }^{3}$ and Suhair SHOMEINA ${ }^{3}$, \\ ${ }^{1}$ College of Applied and Industrial Sciences, University of Bahri, Khartoum, Sudan \\ ${ }^{2}$ College of Natural Resources and Environmental Studies, University of Bahri, Khartoum, Sudan \\ ${ }^{3}$ Cellulose Chemistry and Technology Research Unit, National Centre of Research, Khartoum, Sudan
}

("Corresponding author's e-mail: tarigosmankhider@gmail.com)

Received: 22 January 2020, Revised: 21 April 2020, Accepted: 20 May 2020

\begin{abstract}
This study aims to utilize the pruned branches of Citrus limon in pulping with alkaline pulping methods and to determine the suitability of guar gum to improve the strength properties of pulps and limitations of cutting trees for environmental issues and utilization of lemon branches as horticultural residues. These branches' physical properties exhibited high medium density and very low percentages of bark to wood ratio. The whole chemical components of these raw materials indicated the suitability to a pulp with alkaline cooking methods. In addition, alkaline sulfite anthraquinone with methanol methods gave excellent screened yield (60.1 \%), negligible rejects, bleachable Kappa number 19.5, and best strength properties, especially tensile and strengths. Alkaline sulfite with anthraquinone gave excellent screened yield with a small percentage of rejects and bleachable Kappa number. On the other hand, soda cooking produced pulps with acceptable yield (41.9\%), rejects (3\%), and suitable strengths. The soda anthraquinone pulping methods produced pulp with good yields (56 - $59.7 \%)$. Obviously, anthraquinone's effect in preserving carbohydrates, specifically hemicelluloses, increases the yields and strengths. Guar gum improved pulps' physical properties when added during beating with $(0.25 \%$ on oven-dry Soda-AQ pulps). It clears Citrus limon branches' suitability with an age of 2 years in cooking with all alkaline pulping methods applied.
\end{abstract}

Keywords: Cirtus limon, Physical properties, Chemical composition, Alkaline cooking, Guar gum

\section{Introduction}

Lemon names in different languages are similar to the scientific name Citrus limon Burm family Rutaceae [1]. The lemons originated from Central Asia, the Himalayan Mountains, and northern Myanmar [2]. However, the known countries for the production of lemon worldwide are Argentina, Mexico, Italy, Brazil, Spain, China, India, United States, Turkey, and Iran [3]. Lemon has medicinal properties as reduction of Joints inflammation [4], antioxidant and alcohol liver injury treatment [5] contain essential oils [6], suppression of N-nitrosamine formation [7], source of vitamin C [8], and flavor for food [9].

The dead branches of the lemon tree are removed periodically to improve the growth conditions and fruit quality. This process is called pruning [10-14]. The dead branches usually become wastes, which are burned, especially in developing countries. The rational utilization of these dead branches has added value to the planting of the lemon trees. The pulping of the branches of lemon could be considered as a smart option for maximum utilization of this tree. Soda pulping of citrus branches gave a high yield when anthraquinone is applied during cooking [15]. The addition of guar gum during refining to improve pulps' 
http://wjst.wu.ac.th

physical properties could be considered an attractive option. Guar gum is produced from the seed of Cyamopsis tetragonoloba, a gel-forming galactomannan [16-18]. Guar gum is characterized by swelling property from good hydrogen bond within water and fibers [19].

The present work aimed to evaluate the characteristics of Citrus limon dead branches in terms of physical properties, chemical composition, alkaline pulping, and papermaking characteristics with soda and without anthraquinone, AS-AQ, and ASAM cooking methods. It also evaluates the applicability of guar gum to improve the strength properties of pulps.

\section{Materials and methods}

Nineteen dead branches were collected from 2 years old Citrus limon trees after pruning, randomly selected according to TAPPI standards [20]. The trees were grown in farms in northern Khartoum State. The branches were transported to National Centre for Research in Khartoum, cleaned, cross-cut, and sawn into discs about $2.5 \mathrm{~cm}$. The bark-to-wood ratio was determined as a proportion of the branches (including bark) both by volume and mass. The basic density was measured as the oven-dry mass/green volume of the test specimens according to British Standards [21] and (TAPPI-258-om-02).

Chips for pulping trials were manually prepared for drying according to TAPPI standard (T257-cm02) Figure 1. A composite sample of chips was ground in a star mill, sieved with 40 by 60 mesh fractions, and used for the chemical analysis. The chemical analysis was carried out in accordance with the standard methods of TAPPI standards [20], preparation for chemical analysis (TAPPI-264-cm-97) sampling and testing for moisture (TAPPI-210-cm-93), hot water-soluble (TAPPI-T-207), solvent extraction of wood (TAPPI-204), Pentosans (TAPPI-223-cm-01) alpha-cellulose (TAPPI-203-OS-61), and ash (TAPPI-212) lignin (TAPPI-222), except for the cellulose which was measured according to the Kushner and Hoffer method [22]. Pulping was carried out in a 7-litre capacity rotating autoclave (Figure 2) at a maximum temperature of 170 and $175^{\circ} \mathrm{C}$ for two $h$.

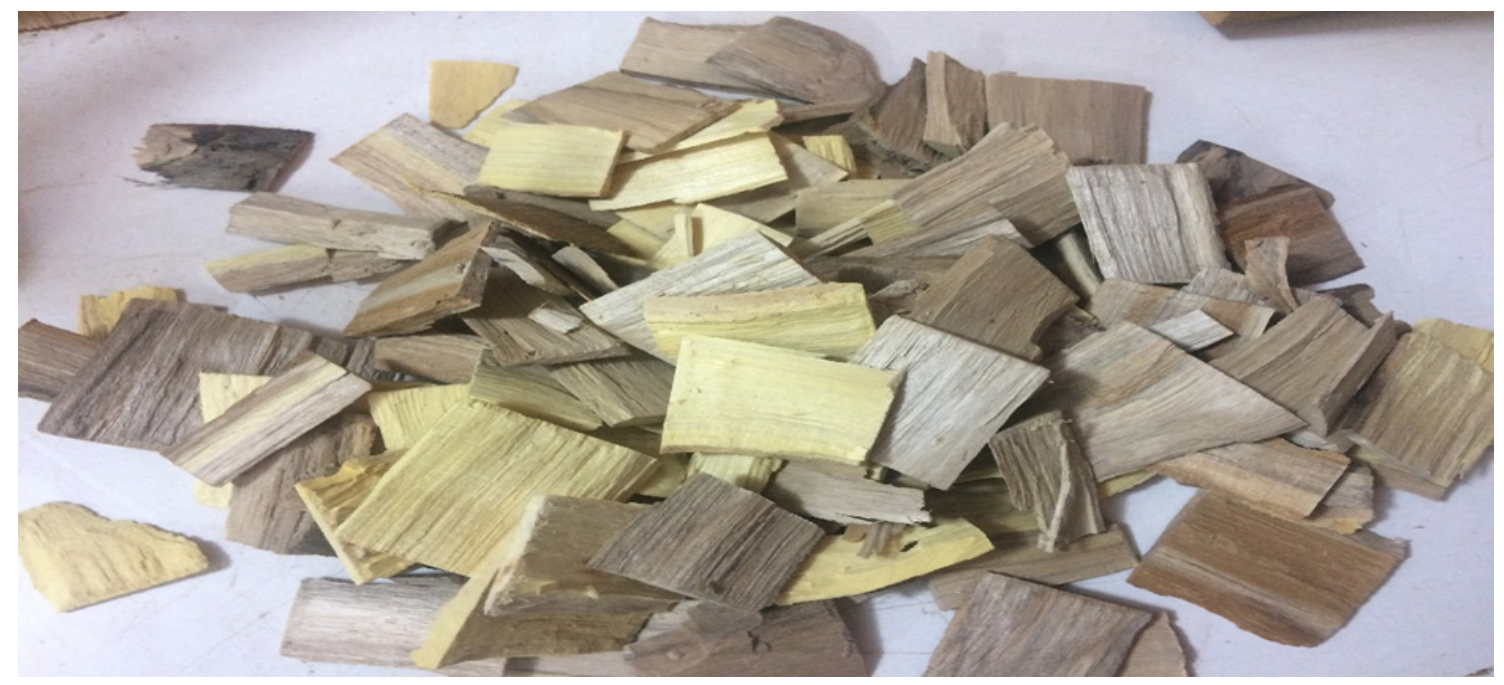

Figure 1 The chips of Citrus limon after drying. 


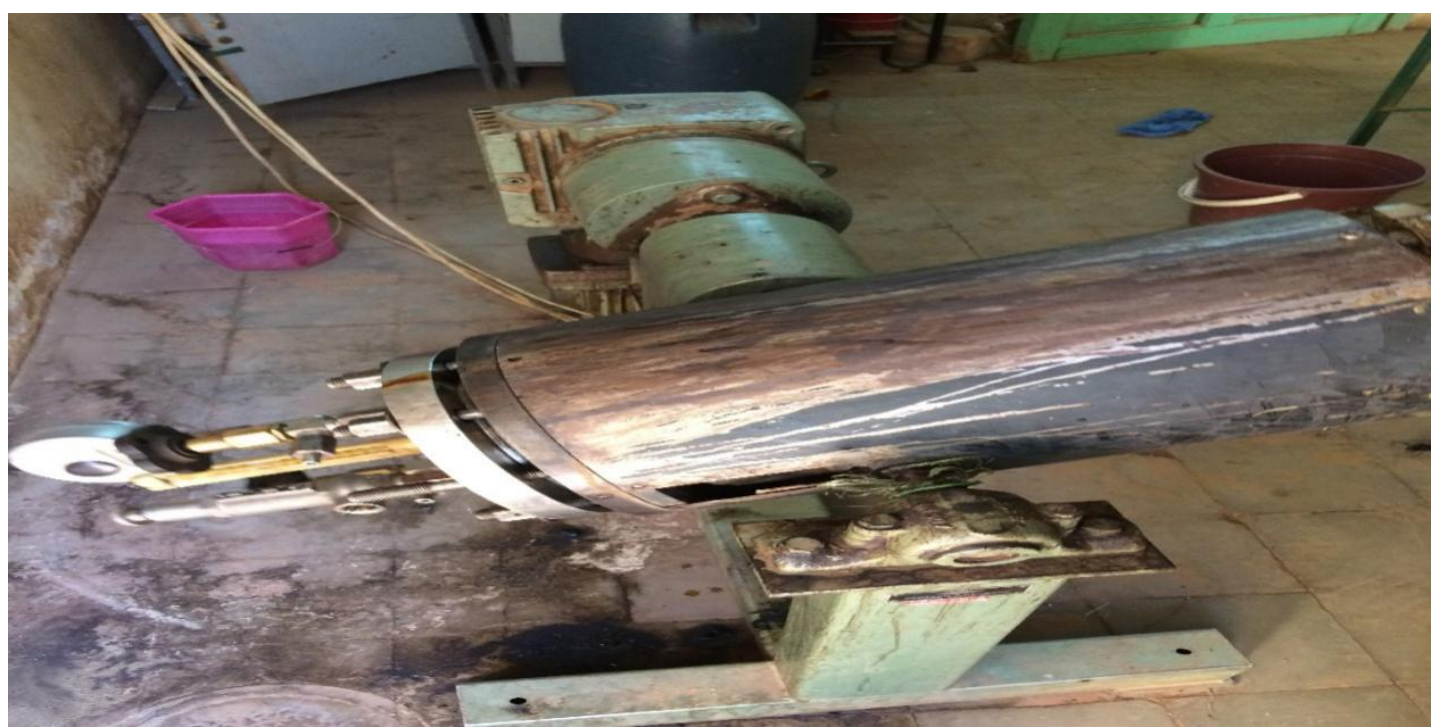

Figure 2 The digester used during pulping of Citrus limon with soda, Soda-AQ, AS-AQ and ASAM methods.

The Lemon chips (Table1) were cooked at different chemical charges of soda and Soda-AQ 12 - 15 $\%$ (as $\mathrm{NaOH}$ ), $17 \%$ for AS-AQ and ASAM with ratio $\mathrm{Na}_{2} \mathrm{SO}_{3}$ to $\mathrm{NaOH}$ ratio 70:30. The anthraquinone (AQ) was added in $0.05 \%$. The methanol was added during ASAM pulping according to [23]. A wood to liquor ratio of 1:4 was used [24,25].

Table 1 Pulping conditions of Citrus limon branches.

\begin{tabular}{lccccc}
\hline Cooking conditions & Soda & Soda-AQ1 & Soda-AQ2 & AS-AQ & ASAM \\
Cook code & CL1 & CL2 & CL3 & CL4 & CL5 \\
\hline Active alkali as $\mathrm{NaOH}, \%$ & 15 & 15 & 12 & 17 & 17 \\
Anthraquinone, \% & - & 0.05 & 0.05 & 0.05 & 0.05 \\
$\mathrm{Na}_{2} \mathrm{SO}_{3}$ to NaOH ratio & - & - & - & $70: 30$ & $70: 30$ \\
Liquor to Citrus limon branches & 4 & 5 & 5 & 5 & 5 \\
Maximum temperature, ${ }^{\circ} \mathrm{C}$ & 170 & 170 & 170 & 170 & 175 \\
Time to maximum temperature, $\min$ & 60 & 60 & 60 & 70 & 70 \\
Time at maximum temperature, $\min$ & 120 & 120 & 120 & 120 & 120 \\
\hline
\end{tabular}

Kappa number was done with TAPPI standards T236-om-99. After pulping, the cooked and screened material (Figure 3) was cleaned with water to remove black liquor, disintegrated at 1,200 rpm for $30 \mathrm{~min}$, at room temperature. The pulp was then refined with Valley beater according to TAPPI-200sp-01 freeness of pulp (Canadian standard method TAPPI-227-om-99), physical testing of pulp sheets 
(TAPPI-220-sp-01). Conditioning of testing atmosphere (TAPPI-402-sp-98), Burst strength (TAPPI-403om-97), Tensile (TAPPI-404-cm-92), grammage (TAPPI-410-om-98), thickness (TAPPI-411-om-97) and ISO standards [26]. The guar gum was added to a pulp during Soda-AQ pulps beating with a very small amount $(0.25 \%$ on oven-dry pulp).

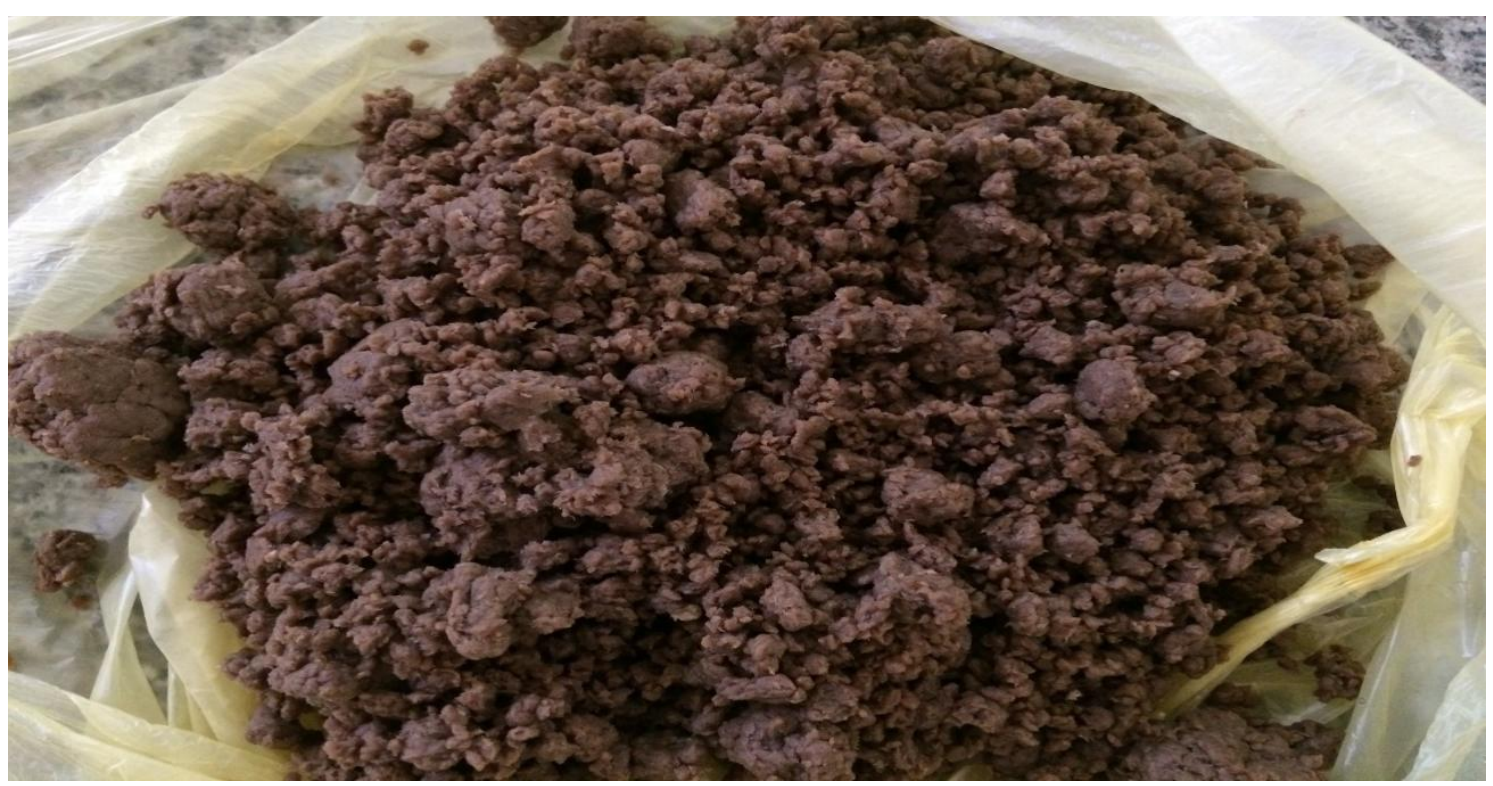

Figure 3 Screened pulps of Citrus limon cooked with soda cooking.

Table 2 Physical properties of Citrus limon branches.

\begin{tabular}{lc}
\hline Physical properties, \% & Limon branches \\
\hline Average age of tree (years) & $2 \pm 0.22$ \\
Moisture content & $7.5 \pm 0.13$ \\
Basic density (oven dry) $\mathrm{Kg} \mathrm{m}^{-3}$ & $572.1 \pm 0.25$ \\
Green density Kg m & -3 \\
Bark to wood ratio by volume & $577.3 \pm 0.33$ \\
Bark to wood ratio by mass & $5.2 \pm 0.34$ \\
\hline
\end{tabular}

\section{Results and discussion}

Pruned branches of 2 years old Citrus limon had a moderately high average basic density of 572.1 $\mathrm{kg} \mathrm{m}-3$ and a green density of $577.3 \mathrm{~kg} \mathrm{~m}-3$ (Table 2). According to Bin's (1970) classification [27], Citrus limon falls within the range for commercial pulpwood (350 - $650 \mathrm{Kg} \mathrm{m}-3)$. According to [28], the pulp yield per unit volume is directly related to basic density as Citrus limon chips are expected to occupy normal digester space for a given pulp making capacity. The wood density is highly related to the cell wall thickness and corresponds to the fiber's collapsibility and conformability. Fibers of moderate density are less flexible; however, the wood of moderately high density is expected to give moderate to 
http://wjst.wu.ac.th

high yield with good quality paper. The average bark - to the wood ratio by mass and volume (Table 2) was low (6.7 and $5.2 \%$, respectively) for pulp woods. It is well known that the presence of bark and dirt influences the quality of pulp, while the presence of bark in low ratios positively affects the economic value of the pulp production by decreasing the cost of transportation and debarking processes.

The moderate ash content of Citrus limon (Table 3) may be attributed to the rapid growth resulting from the need for macronutrients in metabolic activities in the first years. Silica content was more or less negligible. The solubility of hot water, alcohol, and alcohol: cyclohexane (1:2) were low, indicating low extractives in Citrus limon wood with high solubility of $1 \%$. NaOH indicated normal cooking without pretreatments, and standard chemical amounts to be used with high screened yields are expected. However, the normal Kurschner-Hoffer cellulose and high pentosans indicated an excellent yield. On the other hand, the moderate lignin content and high $1 \% \mathrm{NaOH}(18.9 \%)$, as shown in Table 3, is favorable for a reasonable active alkali charge. The high amount of pentosans indicated easy beating and fiber-fiber bonding; however, the low total extractives indicated that there would be no pitch problems and easy cooking.

Table 3 Chemical components of Citrus limon branches from Khartoum State.

\begin{tabular}{lc}
\hline Chemical composition, \% & Limon branches \\
\hline Ash & $3.5 \pm 0.84$ \\
Total Silica & $1.1 \pm 0.23$ \\
Solubility in & \\
$\quad$ Hot water & $2.5 \pm 0.40$ \\
Cold water & $3.0 \pm 0.22$ \\
$\quad$ Alcohol (Ethanol) & $2.3 \pm 0.21$ \\
$\quad$ Ethanol: Cyclohexane $(1: 2)$ & $1.0 \pm 0.34$ \\
Kurchner-Hoffer cellulose & $18.9 \pm 0.14$ \\
Alfa-cellulose & $44.4 \pm 0.23$ \\
Pentosans & $40.1 \pm 0.24$ \\
Lignin & $18.3 \pm 0.11$ \\
Total Extractives & $25.1 \pm 0.35$ \\
Cellulose to lignin ratio & $8.2 \pm 0.22$ \\
\hline
\end{tabular}

The pulping of pruned branches of citrus limon was carried under 4 chemical processes, namely: soda, Soda-AQ, alkaline sulphite anthraquinone (AS-AQ) and alkaline sulphite anthraquinone with methanol ASAM. Optimization of delignification and results of yields were given in Table 4 . 
http://wjst.wu.ac.th

Table 4 Pulping results and strength properties of Citrus limon branches.

\begin{tabular}{lcccccc}
\hline Cooking Conditions & & Soda & Soda-AQ1 & Soda-AQ2 & AS-AQ & ASAM \\
\hline Cooking code & & CL1 & CL2 & CL3 & CL4 & CL \\
\hline Screened yield, \% & $41.9 \pm 0.1$ & $56.0 \pm 0.09$ & $59.7 \pm 0.04$ & $55.4 \pm 0.06$ & $60.1 \pm 0.22$ \\
Rejects, \% & $3 \pm 0.09$ & $0.1 \pm 0.08$ & $2.0 \pm 0.03$ & $4.2 \pm 0.04$ & $0.2 \pm 0.21$ \\
Total yield, \% & $44.9 \pm 0.09$ & $56.1 \pm 0.1$ & $59.7 \pm 0.04$ & $59.6 \pm 001$ & $60.3 \pm 0.22$ \\
Kappa number & & 26.3 N/A & 21.9 N/A & 22.8 N/A & 20.7 N/A & 19.5 N/A \\
Strength properties & & & & & & \\
Beating time, & min & & & & & \\
Tensile index, Nmg ${ }^{-1}$ & 0 & 0.4 & 1.4 & 1.5 & 1.7 & 2.6 \\
& 10 & 1.1 & 2.1 & 2.8 & 3.1 & 4.1 \\
& 15 & 2.8 & 3.2 & 3.3 & 4.1 & 4.5 \\
Burst Index, Kpam ${ }^{2}{ }^{-1}$ & 0 & 0.4 & 0.3 & 0.3 & 0.7 & 1.0 \\
& 10 & 1.0 & 0.9 & 1.3 & 1.8 & 1.9 \\
& 15 & 1.0 & 1.9 & 1.2 & 1.8 & 2.1 \\
Grammage, Cm ${ }^{2}$ & 0 & 106 & 118.8 & 109 & 110 & 111 \\
& 10 & 102 & 119.4 & 99.6 & 100 & 100 \\
& 15 & 101.1 & 117.6 & 100 & 99.5 & 100 \\
& 0 & 17.3 & 16.8 & 17.3 & 16.5 & 15.5 \\
Thickness, mm & 10 & 16.2 & 12.6 & 16.5 & 13.4 & 13.2 \\
& 15 & 10.5 & 11.0 & 9.3 & 10 & 10 \\
\hline & & & & & &
\end{tabular}

$\mathrm{N} / \mathrm{A}=$ not available

The four processes of active alkali charges were in the range (12 - $17 \%$ ) with more or less similar cooking conditions. The slight differences in time to reach the needed maximum temperatures applied to AS-AQ and ASAM methods were increased by $10 \mathrm{~min}$. It seemed that the addition of anthraquinone to soda, AS-AQ, and ASAM trials, and lately methanol to ASAM cooking accelerated the delignification and preserved the carbohydrates [29-34]. The contribution of AQ was supported further by the addition of methanol in ASAM pulping resulted in the lowest Kappa number, 19.5, compared to the other three methods (Table 4). The pulping results for branches of Citrus limon (Table 4) show that this raw material is easy to delignify. With all processes applied, bleachable kappa numbers (19.5 - 26.3) could be reached at good to excellent screened yields (41.9-60.1\%). ASAM pulping resulted in the highest screened yield $(60.1 \%)$ with a negligible amount of rejects $(0.2 \%)$ at bleachable pulp with low kappa number 19.5 .

Comparison of strength properties of different Citrus limon unbleached pulps (Table 4) indicated, in general, the high tensile strength of the ASAM pulps. The high tensile strength, which is mainly based on the fibers' good bonding ability, results from the high carbohydrate content of ASAM pulps due to the high stability of xylan and cellulose in the outer cell wall layers. However, the soda Citrus limon pulp had 
http://wjst.wu.ac.th

lower tensile strength than ASAM and AS-AQ pulps which the lower pentosan preservation can explain during cooking. The overall evaluation of pulp properties showed the superiority of ASAM pulps in all strength properties and grammage and thickness fluctuations. However, the soda process showed inferior results in strength properties. When guar gum was added to Soda-AQ (CL3) dramatically increase the physical properties, especially tensile and burst strengths compared with Soda-AQ (CL2).

\section{Conclusions}

Based on the physical and chemical properties, the pruned branches of Citrus limon could be considered medium-high pulp woods. The cooking of Citrus limon branches with alkaline processes indicated its suitability for pulp and paper production. Soda and Soda-AQ methods can be cooked to bleachable Kappa numbers for bleachable pulps. In ASAM pulping, the effect of anthraquinone and methanol was clearly remarkable, total yield, screened yield bleachable Kappa numbers with both AS-AQ and specifically ASAM process with good to excellent pulp properties.

The rational utilization of Citrus limon pruned branches as in the production of pulp and paper instead of being a waste could be economically and environmentally attractive with need for feasibility studies to complete the technical studies.

\section{Acknowledgements}

The authors are grateful for the students of the University of Bahri, college of Applied and Industrial Sciences, department of Pulp and Paper who did the lab work, Najwa Ahmed Abdelkareem, Elhadi Abduelmageed Mohammod, and Eltaib Adam Edrees.

\section{References}

[1] JH Crane. Lemon growing in the Florida home landscape. UF/IFAS Extension 2019; 1, 1-12.

[2] L Abbate, F Mercati and SFD Bosco. An overview on citrus mal secco disease: Approaches and strategies to select tolerant genotypes in C. limon. Crop Breed. Genet. Genom. 2019; 1, 1-29.

[3] M Mohanapriya, L Ramaswamy and R Rajendran. Health and medicinal properties of lemon (Citrus Limonum). Int. J. Ayurvedic Herb. Med. 2013; 3, 1095-100.

[4] M Pal. Lemon: A versatile fruit of multiple uses. Agric. World 2017; 3, 52-4.

[5] T Zhou, YJ Zhang, DP Xu, F Wang, Y Zhou, J Zheng, Y Li, JJ Zhang and HB Li. Protective effects of lemon juice on alcohol-induced liver injury in mice. Biomed. Res. Int. 2017; 2017, 746351.

[6] NS Dosoky and WN Setzer. Biological activities and safety of Citrus spp. essential oils. Int. J. Mol. Sci. 2018; 19, 1966.

[7] S Rafiq, R Kaul, SA Sofi, N Bashir, F Nazir and GA Nayik. Citrus peel as a source of functional ingredient: A review. J. Saudi Soc. Agric. Sci. 2018; 17, 351-8.

[8] AS Kefi, C Chama, L Kalumba, I Bbole, P Chungu and M Mbambara. Vitamin C levels in lemons (Citrus Limon) grown in Zambia; an opportunity for utilization in fish feeds. J. Agric. Life Sci. $2016 ; 3,37-42$.

[9] MG Veldhuizen, A Siddique, S Rosenthal and LE Marks. Interactions of lemon, sucrose and citric acid in enhancing citrus, sweet and sour flavors. Chem. Senses 2017; 43, 17-26.

[10] DPH Tucker, TA Wheaton and RP Muraro. Citrus tree pruning principles and practices. Florida Cooperative Extension Service, University of Florida, 1994.

[11] F Intrigliolo and G Roccuzzo. Modern trends of Citrus pruning in Italy. Adv. Hort. Sci. 2011; 25, 187-92.

[12] B Martin-Gorriz, IP Castillo and A Torregrosa. Effect of mechanical pruning on the yield and quality of 'Fortune' madarins. Span. J. Agric. Res. 2014; 12, 952-9.

[13] SR Patil, SM Bichkule and AM Sonkamble. Effect of severity and time of pruning on growth, flowering and fruit set of hasta bahar in acid lime. Int. J. Curr. Microbiol. Appl. Sci. 2018; S6, 96874. 
http://wjst.wu.ac.th

[14] AJ Krajewskia and SA Krajewski. Canopy management of sweet orange, grapefruit, lemon, lime and mandarin trees in the tropics: Principles, practices and commercial experiences. Acta Hort. $2011 ; \mathbf{8 9 4}, 65-76$.

[15] A Tutu, M Cicekler and N Kucukbey. Pulp and paper production from bitter orange (Citrus aurantium L.) woods with Soda-AQ method. Kastamonu Univ. Orman Fak. Derg. 2016; 16, 14-8.

[16] D Mudgil, S Barak and BS Khatkar. Guar gum: Processing, properties and food applications-A Review. J. Food Sci. Technol. 2014; 51, 409-18.

[17] SJ Yoon, DC Chu and LR Juneja. Chemical and physical properties, safety and application of partially hydrolized guar gum as dietary fiber. J. Clin. Biochem. Nutr. 2008; 42, 17-7.

[18] K Yu, D Wong, J Parasrampuria and D Friend. Guar gum: Analytical profiles of drug substances and excipients. Vol 24. Elseviers, 1996, p. 243-76.

[19] TD Bradley, A Ball, SE Harding and JR Mitchell. Thermal degradation of guar gum. Carbohydr. Polym. 1989; 10, 205-14.

[20] TAPPI. Standards and suggested methods. TAPPI, New York. Available at: https://www.tappi.org/globalassets/documents/standards/tm_guidelines_complete.pdf, accessed June 2020.

[21] British Standards B.S. 373.1957. The British Standard Methods of Testing Small Clear Specimens of Timber. British Standards Institute, London. Available at: https://www.documentcenter.com/standards/show/BS-373, accessed June 2020.

[22] AV Obolenskaya, VP Tshegolov, GI Akim, NC Kossoviz, NL Emelyannova and IZ Practitcheshie. Raboti po Himii Drevesinii Tzellulozi (in Russian). Lesporm, Moscow, Russia, 1965.

[23] O Kordsachia, B Wandianger and R Patt. Some investigation on ASAM pulping and chlorine free bleaching of eucalyptus from spain. Holz Roh. Werkst. 1992; 50, 85-91.

[24] H Holton. Soda additives softwood pulping: A major new process. Pulp Paper Can. 1977; 78, T218-T223.

[25] P Khristova, S Gabir, S Bentcheva and T Khider. Soda-AQ pulping of four Acacias from Sudan. Cell. Chem. Technol. 1998; 32, 299-307.

[26] ISO Standards. International Organization for Standardization. Available at: https://www.iso.org/committee/45674/x/catalogue, accessed June 2020.

[27] PT Bin. Present status of pulping and papermaking research with special reference to possible utilization of tropical hardwoods. In: Proceedings of the Malaysian Forestry Conference. Malaysia. 1970.

[28] J Casey. Pulp and paper chemistry and chemical technology. Vol I. Interscience Publications, New York, 1980.

[29] P Khristova, O Kordsachia and T Khider. Alkaline pulping with additives of date palm rachis and leaves from Sudan. Bioresour. Technol. 2005; 96, 79-85.

[30] SH Omer, TO Khider, OT Elzaki, SD Mohieldin and SK Shomeina. Application of soda-AQ pulping to agricultural waste (okra stalks) from Sudan. BMC Chem. Eng. 2019; 1, 1-6.

[31] TO Khider, OT Elzaki and SH Omer. Soda and soda-AQ pulping of Albizia lebbeck from Sudan. Suranaree J. Sci. Technol. 2011; 18, 299-30.

[32] TO Khider, SH Omer and OT Elzaki. Pulping and totally chlorine free (TCF) bleaching of Acacia mellifera from Sudan. World Appl. Sci. J. 2012; 16, 1256-61.

[33] SR Masrol, MHI Ibrahim, S Adnan, MR Talib and L Sian. Effect of Soda-Athraqunione pulping variables on durian rind pulp and paper characteristics: A preliminary test. Mater. Sci. Eng. 2017; 226, 1-10.

[34] MS Jahan, M Sarkar and MA Quaiyyum. Pulping of gamari roots (Gmelina arborea). J. Indian Acad. Wood Sci. 2018; 15, 28-32. 